Research, Society and Development, v. 10, n. 10, e309101018813, 2021

(CC BY 4.0) | ISSN 2525-3409 | DOI: http://dx.doi.org/10.33448/rsd-v10i10.18813

\title{
Fermentação do capim-elefante inoculado com bactéria lática do trato digestório de
}

\section{bovinos}

\section{Fermentation of elephant grass inoculated with lactic acid bacteria from the digestive tract of cattle Fermentación de pasto elefante inoculado con bacterias del ácido láctico del tracto digestivo del} ganado

Aniele de Cássia Rodrigues Veloso ORCID: https://orcid.org/0000-0003-0950-3379 Universidade Federal de Minas Gerais, Brasil E-mail: aniele.cassia@gmail.com

Thiago Alves Xavier dos Santos ORCID: https://orcid.org/0000-0003-1922-2490 Universidade Federal de Minas Gerais, Brasil E-mail: thiagoax.17@gmail.com

Lavínia Francine Xavier Santos ORCID: https://orcid.org/0000-0002-1033-3269 Universidade Federal de Minas Gerais, Brasil E-mail: laviniafrancine@hotmail.com

Valdo Soares Martins Júnior

ORCID: https://orcid.org/0000-0002-6919-8639 Universidade Federal de Minas Gerais, Brasil E-mail: valdo-soares1@ @otmail.com

Suze Adriane Fonseca

ORCID: https://orcid.org/0000-0001-8161-2364 Universidade Federal de Minas Gerais, Brasil E-mail: suzeafonseca@gmail.com

Abigair Duarte Matias

ORCID: https://orcid.org/0000-0002-9434-6381 Universidade Federal de Minas Gerais, Brasil E-mail: admzootec@yahoo.com.br

Rafael Bolina Silva

ORCID: https://orcid.org/0000-0001-8958-9808 Universidade Federal de Minas Gerais, Brasil E-mail: rafael.bolina2@ gmail.com

Victor Alugustus Vasconcelos de Oliveira ORCID: https://orcid.org/0000-0002-0384-5565 Universidade Federal de Minas Gerais, Brasil E-mail: victoravoliveira@hotmail.com

Thiago Gomes Dos Santos Braz ORCID: https://orcid.org/0000-0003-1840-7901 Universidade Federal de Minas Gerais, Brasil E-mail: thiagogsbz@hotmail.com Eduardo Robson Duarte

ORCID: https://orcid.org/0000-0002-2205-9412 Universidade Federal de Minas Gerais, Brasil E-mail: duartevet@hotmail.com

\section{Resumo}

O objetivo neste estudo foi avaliar os efeitos da inoculação de uma cepa de bactéria lática do trato digestório de bovinos na fermentação do capim-elefante (Pennisetum purpureum cv. Cameroon) pré-emurchecido. O delineamento experimental foi inteiramente casualizado com os seguintes grupos experimentais: (CONT) Controle sem aditivo, (LACT5) Lactobacillus plantarum a 1,0 × $10^{5}$ Unidades Formadoras de Colônia por grama (UFC/g) de forragem, (LACT9) L. plantarum a $1,0 \times 10^{9} \mathrm{UFC} / \mathrm{g}$ de forragem utilizando-se seis repetições. As perdas de matéria seca, efluente e o pH após 31 dias de fermentação a $37^{\circ} \mathrm{C}$ não foram influenciadas pela inclusão da bactéria. Os grupos experimentais não influenciaram as populações Lactobacillus spp., Diplococos e fungos leveduriformes e miceliamos. Entretanto, a inoculação dessa bactéria lática na forragem reduz em aproximadamente um $\log \mathrm{de}$ UFC/g o total da população de enterobactérias e não permite o crescimento daquelas não fermentadoras de lactose. Esses resultados apontam 
um potencial promissor para utilização dessa cepa para redução desses patógenos nas silagens do capim elefante. Palavras-chave: Cameroon; Enterobacteriaceae; Inoculação; Lactobacillus plantarum; Probióticos.

\begin{abstract}
The objective of this work was to evaluate the effects of inoculation of a strain of lactic bacteria from the digestive tract of cattle on the fermentation of elephant grass (Pennisetum purpureum cv. Cameroon). The experimental design was completely randomized with six replications of the of the following experimental groups: (CONT) Control without additive, (LACT5) Lactobacillus plantarum at Colony Forming Units per gram (CFU/g) of forage, (LACT9) L. plantarum at $1.0 \times 10^{9} \mathrm{CFU} / \mathrm{g}$ of forage. Losses of dry matter and effluent and $\mathrm{pH}$ after 31 days of fermentation at $37^{\circ} \mathrm{C}$ were not influenced by the inclusion of the bacteria. The experimental groups did not vary their populations of lacti bacteria, yeast and mycelial fungi. However, the inoculation of this lactic bacterium reduces the population of enterobacteria and does not allow the growth of those non-fermenters of lactose. These results point to a promising potential for using this strain to reduce these pathogens in elephant grass silage.
\end{abstract}

Keywords: Cameroon; Enterobacteriaceae; Inoculation; Lactobacillus plantarum; Probiotics.

\title{
Resumen
}

El objetivo de este estudio fue evaluar los efectos de la inoculación de una cepa de bacterias del ácido láctico del tracto digestivo de bovinos sobre la fermentación de pasto elefante marchito (Pennisetum purpureum cv. Camerún). El diseño experimental fue completamente al azar con los siguientes grupos experimentales: (CONT) Control sin aditivo, (LACT5) Lactobacillus plantarum a $1.0 \times 10^{5}$ Unidades Formadoras de Colonias por gramo (UFC / g) de forraje, (LACT9) $L$. plantarum a $1.0 \times 10^{9} \mathrm{UFC} / \mathrm{g}$ de forraje utilizando seis repeticiones. Las pérdidas de materia seca, efluentes y pH luego de 31 días de fermentación a $37 \mathrm{oC}$ no fueron influenciadas por la inclusión de las bacterias. Los grupos experimentales no influyeron en las poblaciones de Lactobacillus spp., Diplococci y levaduras y hongos miceliales. Sin embargo, la inoculación de esta bacteria láctica en el forraje reduce la población total de enterobacterias en aproximadamente un logaritmo de UFC / gy no permite el crecimiento de aquellos fermentadores sin lactosa. Estos resultados apuntan a un potencial prometedor para el uso de esta cepa para reducir estos patógenos en ensilajes de pasto elefante.

Palabras clave: Camerún; Enterobacteriaceae; Inoculación; Lactobacillus plantarum; Probióticos.

\section{Introdução}

Durante o Processo de ensilagem são encontrados microrganismos autóctones da forrageira, a microbiota epífita (Guimarães et al., 2018). Entretanto a dinâmica das populações desses microrganismos varia de acordo com fatores do ambiente, do manejo da forrageira e características intrínsecas da planta, como teor de matéria seca e de carboidratos solúveis (Ferreira et al., 2013). Frequentemente, erros durante a ensilagem podem favorecer o crescimento de microrganismos indesejáveis e causar perdas de matéria seca e na qualidade da silagem (Borreani et al., 2018).

O uso de aditivos microbianos é uma das opções para minimizar fermentações indesejáveis na silagem, pois aumenta a população e o crescimento das bactérias de ácido lático (BAL) no início do processo fermentativo. Os principais microrganismos utilizados nesses aditivos são as bactérias Lactobacillus plantarum, Lactobacillus acidophilus, Pediococcus acidilactici, Pediococcus pentosaceus e Enterococcus faecium (Bumbieris et al., 2011).

Bactérias láticas têm sido amplamente utilizadas para melhorar a qualidade da fermentação, pois convertem carboidrato solúvel em ácidos orgânicos. Consequentemente, há redução do $\mathrm{pH}$ e inibição do crescimento de enterobactérias e bactérias dos gêneros Listeria, Bacillus, Clostridium e de bactérias láticas heterofermentativas (Ferreira et al., 2014; Zhang et al., 2019). Portanto, o uso de bactérias láticas representa uma importante ferramenta para a produção de silagens de boa qualidade, reduzindo a presença de patógenos (Ferreira et al., 2013).

Em estudos anteriores, nosso grupo de pesquisa identificou e caracterizou uma cepa de Lactobacillus sp. proveniente do trato digestório de bezerros que apresentou potencial probiótico, demonstrando antagonismo contra cepas de Escherichia coli causadora de colibacilose de bezerros. Esta cepa Lactobacillus plantarum, apresenta a mesma espécie utilizada em alguns inoculantes comerciais para silagens. Assim, o objetivo foi avaliar os efeitos da inoculação dessa cepa de bactéria lática autóctone do trato digestório de bovino na fermentação in vitro do capim-elefante (Pennisetum purpureum cv. Cameroon) pré-emurchecido. 


\section{Metodologia}

\subsection{Bactéria lática avaliada}

O isolado de Lactobacillus plantarum foi proveniente de fezes de bezerro desmamado Girolando criado no Norte de Minas Gerais. Para a identificação dessa bactéria, o DNA total foi submetido à amplificação por meio da reação em cadeia da polimerase (PCR) utilizando os iniciadores 27F (5'-AGAGTTTGATCCTGGCTCAG-3') e 1492R (5'-GGTTACCTTGTTACGACTT-3'), como descrito por Lane (1991), e o gene 16S rRNA foi analisado em sequenciador automático MegaBACE® 1000 (GE Life Sciences, Chicago, EUA) no laboratório Myleus Biotechnology (Belo Horizonte, Brasil). A sequência do gene foi verificada pelo SeqScanner Software® v1.0 (Applied Biosystems, Foster City, EUA) e comparada com o banco de dados NCBI pelo servidor BLAST (http://www.ncbi.nlm.nih.gov/BLAST/). Adicionalmente à essa análise, a cepa bacteriana apresentou escores de identificação maiores que 2,0 quando analisados por espectrometria de massa com ionização por dessorção a laser assistida por matriz (MALDI-TOF MS), usando o software MALDI-Biotyper v 2.0. A bactéria foi selecionada por apresentar resistência ao pH ácido, resistir a sais biliares e apresentar antagonismos contra cepas de Escherichia coli causadoras de colibacilose em bezerros (Veloso, 2016).

\subsection{Forrageira utilizada}

O capim-elefante (Pennisetum purpureum cv. Cameroon) foi cultivado em fazenda situada em Montes Claros, no norte de Minas Gerais, Brasil ( $16^{\circ} 43^{\prime}$ S e $44^{\circ} 52^{\prime}$ W). A temperatura média anual da região é de $24,2^{\circ} \mathrm{C}$, com clima quente e seco com duas estações bem definidas, seca de abril a outubro e período chuvoso novembro a março (Alvares et al., 2013).

A forragem foi cortada em abril de 2019, a $10 \mathrm{~cm}$ do nível do solo, manualmente, quando a forrageira possuía aproximadamente 3 metros de altura. Posteriormente, foi picada em ensiladora estacionária e o tamanho das partículas foi padronizado em aproximadamente $2 \mathrm{~cm}$. O material foi pré-secado ao sol durante 2 horas e acondicionado em sacos de plásticos.

Determinou-se a matéria seca da forragem pré-secada em analisador de umidade (Shimadz modelo MOC63, Japão), que indicou teor de 40\%. O pH da forragem também foi mensurado, utilizando método descrito por Silva e Queiroz (2002). Promoveuse a diluição de 9 gramas de forragem fresca e pré-secada em $60 \mathrm{ml}$ de água destilada e leitura com um medidor de pH digital, modelo PG1800, após 30 minutos de repouso e constatou o pH da forragem de 5,8.

\subsection{Análises microbiológicas}

Para as análises microbiológicas, todas as amostras da forragem fresca ou fermentada foram manipuladas em capela de fluxo laminar. Cinco gramas da forragem desidratada foram diluídos em $45 \mathrm{ml}$ de solução $\mathrm{NaCl} 0,9 \%$ estéril e agitados por 5 minutos em vórtex. Posteriormente, quatro alíquotas de $10 \mu \mathrm{l}$ das diluições de $10^{-1}$ a $10^{-10}$ foram inoculadas em placas de Petri estéreis contendo o meio ágar MRS (Merck KGaA®, Darmstadt, Alemanha) para bactérias láticas, ágar Potato Dextrose (KASVI®, Terámo, Itália) contendo $1,5 \%$ de solução de cloranfenicol (10\%/v) para o crescimento de fungos e ágar MacConkey (KASVI®, Terámo, Itália), para o crescimento de Enterobacteriaceae. As placas de MRS foram incubadas a $37^{\circ} \mathrm{C}$ por 48 horas em jarras de anaerobiose com reatores de dióxido de carbono (Permution ${ }^{\circledR}$, Curitiba, PR, Brasil).

As placas de MacConkey e Agar Potato Dextrose foram incubadas a $37^{\circ} \mathrm{C}$ em estufa B.O.D. e monitoradas até dois e sete dias, respectivamente. As unidades formadoras de colônias por gramas (UFC/g) foram quantificadas e diferenciadas conforme aspectos morfológicos (coloração, tamanho e forma da colônia) com o auxílio de um contador de colônias (Murray et al., 2007). Esses procedimentos foram realizados em triplicata. Foi observada elevada contagem de fungos leveduriformes $\left(8,3 \times 10^{7} \mathrm{UFC} / \mathrm{ml}\right.$

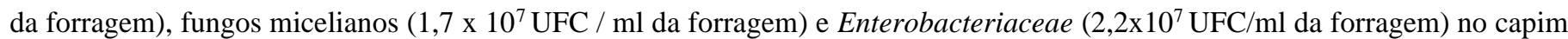


antes de ser ensilado.

\subsection{Procedimentos experimentais}

Utilizou-se o delineamento inteiramente casualizado com três grupos experimentais e seis repetições, sendo: (CONT). Controle sem aditivo, (LACT5) L. plantarum inoculado a 1,0 $\times 10^{5} \mathrm{UFC} / \mathrm{g}$ de peso fresco da forragem e (LACT9) na concentração $1,0 \times 10^{9} \mathrm{UFC} / \mathrm{g}$ de peso fresco.

A bactéria foi avaliada em fase logarítmica após crescimento em meio líquido contendo 2,5\% de fubá de milho, farinha de soja e açúcar. Para inoculação, as amostras de \pm 26 gramas do capim foram misturadas a 9 ml de água destilada e 1,1 ml do inóculo, com massa específica de $0,50 \mathrm{~kg} / \mathrm{dm}^{3}$ de matéria seca. O controle recebeu $9 \mathrm{ml}$ de água destilada e $1,1 \mathrm{ml}$ do meio de cultura composto por 2,5\% de fubá, farinha de soja e açúcar, sem a bactéria. A adição da água destilada estéril corrigiu a matéria seca da forragem pré-ensilada para $28,8 \%$.

Posteriormente a forragem contendo ou não a bactéria lática foi acondicionada em tubos Falcon de 50ml dotados de dreno para efluentes e válvula para escape de gases. Na parte inferior do tubo foram incluídos $2 \mathrm{~g}$ de areia lavada e seca para recuperação do efluente e disco de pano com diâmetro de $27 \mathrm{~mm}$ para impedir aderência da areia à forragem. Nas tampas foram instaladas válvulas de borracha para o escape de gases. Os frascos foram fechados, vedados e armazenados em estufa B.O.D. (Luca-161/01, São Paulo, Brasil) a $37^{\circ} \mathrm{C}$ durante 31 dias.

Inicialmente foi mensurado o peso dos frascos vazios com tampa, areia seca e o disco de pano em balança analítica. Foram também pesados, após a adição da forragem e os respectivos inóculos. Após 31 dias de fermentação, os frascos foram novamente pesados para determinação de perda de gases e efluente.

A perda por gases foi estimada pela diferença entre o peso de massa seca inicial e final dos silos experimentais em relação à quantidade de massa seca ensilada, descontados o peso do conjunto na ensilagem e na abertura, conforme a equação:

$$
\mathrm{PG}(\%)=[(\mathrm{PTen}-\mathrm{PTab}) / \mathrm{MSen}] \times 100
$$

Em que:

PG $(\%)=$ Perda por gases $(\%)$;

PTen $=$ Peso do tubo cheio na ensilagem $(\mathrm{g})$;

PTab = Peso do tubo cheio imediatamente antes da abertura $(\mathrm{g})$;

MSen = Quantidade de massa seca de forragem na ensilagem $(\mathrm{g})$;

Já a quantificação do efluente produzido, foi realizada conforme a fórmula:

$$
\mathrm{EF}\left(\mathrm{g} \mathrm{kg}^{-1}\right)=[(\mathrm{PEab}-\mathrm{PEen}) / \mathrm{MVFE}] \times 100
$$

Onde:

$\mathrm{EF}=$ Produção de efluente $(\mathrm{g} / \mathrm{kg}$ de massa verde);

PEab = Peso da estrutura (silo + areia úmida + tela) após abertura $(\mathrm{kg})$;

PEen $=$ Peso da estrutura $($ silo + areia seca + tela $)$ na ensilagem $(\mathrm{kg})$;

MVFE = Massa verde de forragem ensilada $(\mathrm{kg})$.

Após o período de fermentação, toda forragem foi retirada do tubo, pesada em balança analítica (Marte ay220, Shimadzu Corporation, Minas Gerais, Brasil), homogeneizada e separada em duas sub amostras de 4 gramas para mensuração do pH inicial e pH após 48 horas, com intuito de determinar a estabilidade aeróbica da silagem.

Para o cultivo microbiano, o material foi manipulado em capela de fluxo laminar. Dois gramas da forragem foram diluídos em $18 \mathrm{ml}$ de solução de $\mathrm{NaCl}$ 0,9\% estéril, homogeneizada para diluição decimais seriadas. Posteriormente alíquotas das diluições 
foram inoculadas em placas de Petri contendo meios de cultura, como descrito anteriormente para o cultivo de fungos, bactérias láticas e Enterobacteriaceae.

A identificação dos gêneros de bastonetes Gram Negativos aeróbios e anaeróbios facultativos mais frequentes ocorreu após reisolamento em placas contendo meio ágar MacConkey em estufa a $37^{\circ} \mathrm{C}$ por 24 horas. Após o crescimento exponencial, cada isolado foi inoculado em tubos contendo meio Rugai e Araújo, modificado por Pessoa e Silva Mbiolog. Nessa classificação foram consideradas a capacidade de produção de indol e sulfetos e gases, a utilização de triptofano, lisina, glicose, sacarose, ureia e a motilidade (Murray et al., 2007).

Para a identificação dos gêneros de fungos micelianos foram realizados microcultivos de 34 isolados provenientes das placas de meio Ágar Sabouraud (ACUMEDIA®, Michigan, Estados Unidos). As estruturas micromorfológicas foram evidenciadas em microscópio óptico nas objetivas de 10 e 40X, considerando as características típicas de cada gênero de fungo (Dugan, 2006).

\subsection{Análises estatísticas}

Os dados foram submetidos ao teste de normalidade e homogeneidade. Quando apresentaram distribuição normal, foram submetidos a análise de variância, sendo as médias comparadas por teste Duncan a 5\% de probabilidade. Quando não apresentaram distribuição normal, os dados foram submetidos à análise não paramétrica utilizando-se o teste de Kruskal-Wallis. Todos os dados foram analisados no pacote estatístico SAEG 9.2.

\section{Resultados e Discussão}

Não foram observadas diferenças significativas entres os tipos de inoculantes sobre os parâmetros de qualidade relacionados à silagem $(\mathrm{P}>0,05)$ (Tabela 1). Segundo Yuan et al., (2015) a L. plantarum é uma bactéria de ácido lático homofermentativa ou heterofermentativa facultativa (LAB) capaz de fermentar diferentes substratos e produzir rapidamente grandes quantidades de ácido lático. Isso não foi observado no presente trabalho, possivelmente devido ao baixo teor de carboidratos solúveis disponível para a bactéria.

Tabela 1: Perdas gasosas, efluentes, $\mathrm{pH}$ e estabilidade aeróbica do capim-elefante em capim-elefante (Pennisetum purpureum cv. Cameroon) fermentado inoculado com uma cepa de Lactobacillus plantarum autóctone de bovino e o controle não inoculado.

\begin{tabular}{|c|c|c|c|c|c|c|}
\hline \multirow{2}{*}{ Variável } & \multicolumn{3}{|c|}{ Grupos Experimentais } & \multirow{2}{*}{$\begin{array}{l}\text { Desvio } \\
\text { padrão }\end{array}$} & \multirow{2}{*}{$\begin{array}{c}\text { Erro } \\
\text { padrão }\end{array}$} & \multirow{2}{*}{$\begin{array}{c}\mathrm{P} \\
\text { valor }\end{array}$} \\
\hline & CONT & LAC5 & LAC9 & & & \\
\hline Perdas gasosas (\%) & 15,32 & 17,94 & 12,38 & 2,79 & 1,13 & 0,318 \\
\hline Efluentes $(\mathrm{g} / \mathrm{kg})$ & 0,26 & 0,15 & 0,75 & 0,32 & 0,13 & 0,947 \\
\hline $\mathrm{pH}$ na abertura & 5,95 & 6,15 & 6,05 & 0,06 & 0,02 & 0,909 \\
\hline pH após 48 horas & 6,55 & 8,38 & 7,64 & 0,42 & 0,17 & 0,065 \\
\hline Diferença de $\mathrm{pH}^{*}$ & 0,72 & 2,23 & 1,59 & 0,33 & 0,13 & 0,254 \\
\hline
\end{tabular}

CONT: controle; LACT5: Lactobacillus plantarum (10 UFC/g); LACT9: Lactobacillus plantarum $\left(10^{9} \mathrm{UFC} / \mathrm{g}\right)$; Diferença de $\mathrm{pH} *=\mathrm{pH} 48 \mathrm{~h}$ menos $\mathrm{pH}$ da abertura.

Fonte: Autores (2021)

Não houve efeito dos inoculantes sobre a produção de efluentes (Tabela 1). Esse resultado poderia ter sido influenciado pelo teor de matéria seca inicial. Por outro lado, variações na produção de efluentes estão mais associadas às características físicas da silagem do que características microbiológicas (Tomaz et al., 2018). A produção de efluentes pode ocorrer em silagens de capim 
excessivamente úmidas, momento no qual apresentam melhor perfil nutricional (Daniel et al., 2019) e estão mais suscetíveis a fermentações indesejáveis. Dessa forma, as estratégias de pré-secagem e uso de aditivos tem sido importante para reduzir o risco de deterioração e perdas de efluentes (Nussio, 2005).

$\mathrm{O}$ pH na abertura não foi influenciado pelas inoculações da bactéria e apresentou média de 6,05 \pm 0,06, valor de pH superior ao da forragem antes da fermentação $(5,8)$. Essa média pode ser considerada alta e pode ser indicativo de fermentações indesejáveis e deterioração da silagem. Segundo McDonald (1991), o pH ideal da silagem deve estar abaixo de 4,2. Ribeiro et al., (2014), em estudo com silagem do capim-elefante colhido com 1,8 m de altura e emurchecido, observaram silagem com pH de 3,7, valor inferior ao observado nesse estudo.

Da mesma forma, o pH após $48 \mathrm{~h}$ da abertura também não foi influenciado pelos inóculos (Tabela 1). A diferença de pH após a abertura de silos de forrageiras é considerada um indicativo de perda da estabilidade aeróbica, pois quanto maior o $\mathrm{pH}$ atingido, em menor intervalo de tempo após abertura, menos estável é a silagem.

A inoculação da cepa bacteriana não promoveu elevação de bactérias láticas no capim fermentado após 31 dias (Tabela 2). A utilização do capim com 3 metros de idade pode ter sido um fator comprometedor para o crescimento da bactéria inoculada, uma vez que apresentam baixos teores de carboidratos solúveis para serem utilizados pela bactéria.

Após a fermentação, observou-se baixa contagem de Enterobacteriaceae, com média de 6,85 × $10^{2} \mathrm{UFC} / \mathrm{g}$, indicando que a fermentação reduziu essas bactérias em relação a população inicial (Tabela 3). A presença de Enterobacteriaceae prejudica o processo de conservação da forragem, principalmente nos primeiros dias de ensilagem, quando há uma maior concentração de oxigênio. Em condições normais, na ausência de oxigênio, ocorre a diminuição do pH, inibindo rapidamente a população dessas bactérias (Guimarães et al., 2018).

Contudo, constatou-se redução de aproximadamente um log de UFC/g de forragem fermentada inoculados com LACT5 ou LACT9 na população de bastonetes Gram Negativos aeróbios e anaeróbios facultativos (Tabela 3). Adicionalmente, essa inoculação inibiu o crescimento de Enterobacteriaceae não fermentadoras de lactose, como aquelas do gênero Salmonella, responsáveis por graves infecções intestinais em humanos e animais (Maijala et al., 2005).

$\mathrm{Na}$ forragem fermentada, a quantificação média de leveduras foi de 5,27 × $10^{6} \mathrm{UFC} / \mathrm{g}$ e não foi influenciada pelos inóculos utilizados (Tabela 4). A presença desses microrganismos é indesejável, pois consomem carboidratos solúveis (CHTS) e convertem em etanol, dióxido de carbono e água durante a fase de armazenamento e consomem ácido lático após abertura do silo, reduzindo a estabilidade aeróbica. Ao consumirem CHTS no início do processo fermentativo, esses fungos prejudicam o desenvolvimento das bactérias do ácido lático, promovendo aumento do $\mathrm{pH}$, elevação das perdas de matéria seca e aumento na proporção de fibras (Evangelista et al., 2009).

Tabela 2: Média de unidades formadoras de colônias por grama (UFC/g) e desvio padrão (D.P.) da população de bactérias láticas (BAL) em capim-elefante (Pennisetum purpureum cv. Cameroon) fermentado após inoculação com uma cepa de Lactobacillus plantarum autóctone de bovino.

\begin{tabular}{lcccccc}
\hline Grupos & $\begin{array}{c}\text { Lactobacillus } \\
\text { spp. }\end{array}$ & DP & Diplococos & DP & Total BAL & D.P \\
\hline CONT & $6,36 \times 10^{7}$ & $\pm 7,97 \times 10^{3}$ & $4,74 \times 10^{6}$ & $\pm 2,18 \times 10^{3}$ & $6,83 \times 10^{7}$ & $\pm 8,27 \times 10^{3}$ \\
LACT5 & $2,69 \times 10^{7}$ & $\pm 5,19 \times 10^{3}$ & $4,67 \times 10^{6}$ & $\pm 2,16 \times 10^{3}$ & $3,16 \times 10^{7}$ & $\pm 5,62 \times 10^{3}$ \\
LACT9 & $2,24 \times 10^{7}$ & $\pm 4,73 \times 10^{3}$ & $4,17 \times 10^{6}$ & $\pm 2,04 \times 10^{3}$ & $2,66 \times 10^{7}$ & $\pm 5,51 \times 10^{3}$ \\
Média geral & $3,76 \times 10^{7}$ & $\pm 5,96 \times 10^{3}$ & $4,52 \times 10^{6}$ & $\pm 2,13 \times 10^{3}$ & $4,22 \times 10^{7}$ & $\pm 6,49 \times 10^{3}$ \\
P-valor & 0,8503 & & 0,3526 & & 0,1839 & \\
\hline
\end{tabular}

Nota: CONT= controle; LACT5: Lactobacillus plantarum $\left(10^{5} \mathrm{UFC} / \mathrm{g}\right)$; LACT9: Lactobacillus plantarum $\left(10^{9} \mathrm{UFC} / \mathrm{g}\right)$.

Fonte: Autores (2021). 
Tabela 3: Média de unidades formadoras de colônias por grama (UFC/g) e desvio padrão (D.P.) da população de bastonetes Gram negativos, anaeróbios facultativos em capim-elefante (Pennisetum purpureum cv. Cameroon) fermentado após inoculação com uma cepa de Lactobacillus plantarum autóctone de bovino e o controle não inoculado.

\begin{tabular}{lcccccc}
\hline Grupos experimentais & LAC + & D.P. & LAC - & D.P. & Total & Enterobac \\
& & & & & & D.P. \\
\hline CONT & - & - & $1,67 \times 10^{3}$ & $\pm 4,08 \times 10^{1}$ & $1,67 \times 10^{3}$ & $\pm 4,08 \times 10^{1}$ \\
LACT5 & $1,11 \times 10^{2}$ & $\pm 1,01 \times 10^{1}$ & - & - & $1,11 \times 10^{2}$ & $\pm 1,05 \times 10^{1}$ \\
LACT9 & $2,78 \times 10^{2}$ & $\pm 1,67 \times 10^{1}$ & - & - & $2,78 \times 10^{2}$ & $\pm 1,67 \times 10^{1}$ \\
Média geral & $1,30 \times 10^{2}$ & $\pm 9,07$ & $5,56 \times 10^{2}$ & $\pm 1,36 \times 10^{1}$ & $6,85 \times 10^{2}$ & $\pm 2,27 \times 10^{1}$ \\
P-valor & 0,399 & & 0,559 & & 0,996 &
\end{tabular}

Nota: CONT= controle; LACT5: Lactobacillus plantarum (10 $\left.0^{5} \mathrm{UFC} / \mathrm{g}\right)$; LACT9: Lactobacillus plantarum (10 $\left.{ }^{9} \mathrm{UFC} / \mathrm{g}\right)$; Enterobac.: Enterobacteriaceae; LAC+: Bactérias fermentadoras de lactose; LAC-: Bactérias não fermentadoras de lactose.

Fonte: Autores (2021).

Tabela 4: Média de unidades formadoras de colônias por grama (UFC/g) e desvio padrão (D.P.) da população de fungos em capim-elefante (Pennisetum purpureum cv. Cameroon) fermentado após inoculação com uma cepa de Lactobacillus plantarum autóctone de bovino e o controle não inoculado.

\begin{tabular}{lclcccc}
\hline $\begin{array}{l}\text { Grupos } \\
\text { Experimentais }\end{array}$ & Leveduras & D.P. & Fungos micelianos & D.P. & $\begin{array}{c}\text { Total de } \\
\text { fungos }\end{array}$ & D.P. \\
\hline CONT & $3,49 \times 10^{6}$ & $\pm 1,87 \times 10^{3}$ & $6,60 \times 10^{5}$ & $\pm 8,13 \times 10^{2}$ & $4,15 \times 10^{6}$ & $\pm 2,04 \times 10^{3}$ \\
LACT5 & $7,49 \times 10^{6}$ & $\pm 2,74 \times 10^{3}$ & $1,12 \times 10^{8}$ & $\pm 1,06 \times 10^{4}$ & $1,19 \times 10^{8}$ & $\pm 1,09 \times 10^{4}$ \\
LACT9 & $4,84 \times 10^{6}$ & $\pm 2,20 \times 10^{3}$ & $2,86 \times 10^{7}$ & $\pm 5,35 \times 10^{3}$ & $3,35 \times 10^{7}$ & $\pm 5,79 \times 10^{3}$ \\
Média geral & $5,27 \times 10^{6}$ & $\pm 2,27 \times 10^{3}$ & $4,71 \times 10^{7}$ & $\pm 5,58 \times 10^{3}$ & $5,24 \times 10^{7}$ & $\pm 6,24 \times 10^{3}$ \\
P-Valor & 0,586 & & 0,837 & & 0,693 & \\
\hline
\end{tabular}

Nota: CONT= controle; LACT5: Lactobacillus plantarum $\left(10^{5} \mathrm{UFC} / \mathrm{g}\right)$; LACT9: Lactobacillus plantarum (10 $\left.{ }^{9} \mathrm{UFC} / \mathrm{g}\right)$.

Fonte: Autores (2021).

Após o processo de fermentação das forragens é desejável que ocorre a redução de leveduras. Sabe-se que populações elevadas de leveduras no início do processo fermentativo, como observado para o capim avaliado neste presente estudo, podem prejudicar a fermentação em função da competição com as bactérias do ácido lático (BAL) desejáveis (Driehuis, 2011).

Os fungos micelianos foram detectados na forragem conservada com média de $4,71 \times 10^{7} \mathrm{UFC} / \mathrm{g}$ (Tabela 4) e suas concentrações após a fermentação também não foram influenciados pelos inóculos utilizados. Esses microrganismos degradam grande variedade de nutrientes, incluindo açúcares, ácido lático e carboidratos estruturais. A presença desses eucariotos na silagem indica que possivelmente ainda existia oxigênio nos silos experimentais, permitindo aumento da população aeróbia. A presença desses fungos também poderia estar associada à produção de micotoxinas que causam danos à saúde dos animais e do homem.

O uso da L. plantarum do trato digestório bovino não foi eficiente na redução do crescimento de fungos indesejáveis. Esse resultado poderia ser atribuído à metodologia e ao tipo de silo experimental utilizados. Acredita-se que houve entrada de oxigênio capaz de estimular o crescimento de diversas espécies de fungos micelianos.

$\mathrm{Na}$ forragem fermentada foram identificados 34 isolados fúngicos (Tabela 5). Os gêneros mais frequentes foram o Aspergillus e o Monascus que corresponderam a $35,29 \%$ e $26,47 \%$ dos isolados respectivamente (Tabela 5). A presença de 
Monascus ruber foi constatada em forragem fermentada inoculada com LACT5. Essa espécie está associada à produção da micotoxina monacolina K, que têm a capacidade de diminuir a biossíntese de colesterol e os níveis de colesterol total (Silva e Xará, 2013). Esse fungo também possui a micotoxina citrinina que possui metabólito tóxico, tendo efeito antibacteriano, causando toxicidade hepática e renal (Renhe et al., 2006; Silva \& Xará, 2013).

Tabela 5: Distribuição de gêneros de fungos micelianos isolados da silagem de capim-elefante (Pennisetum purpureum cv. Cameroon) após fermentação com uma cepa de Lactobacillus plantarum autóctone de bovino.

\begin{tabular}{|c|c|c|c|c|c|c|c|}
\hline \multirow{2}{*}{ Gêneros/ espécies } & \multirow{2}{*}{$\frac{\text { Total }}{\mathrm{N}}$} & \multicolumn{2}{|c|}{ CONTR } & \multicolumn{2}{|c|}{ LACT5 } & \multicolumn{2}{|c|}{ LACT9 } \\
\hline & & $\mathrm{n}$ & $\% *$ & $\mathrm{n}$ & $\%$ & $\mathrm{n}$ & $\%$ \\
\hline Aspergillus spp. & $12 * *$ & 5 & 14,70 & 5 & 15,70 & 2 & 5,88 \\
\hline Aspergillus sp. & 2 & 1 & 2,94 & 1 & 2,94 & - & - \\
\hline A. fumigatus & 3 & - & - & 3 & 8,82 & - & - \\
\hline A. nidulans & 1 & - & - & 1 & 2,94 & - & - \\
\hline A. terreus & 6 & 4 & 11,76 & - & - & 2 & 5,88 \\
\hline Monascus ruber & 9 & - & - & 9 & 26,47 & - & - \\
\hline Trichoderma spp. & 1 & - & - & - & - & 1 & 2,94 \\
\hline Total & 34 & & & & & & \\
\hline
\end{tabular}

CONTR: controle; LACT5: Lactobacillus plantarum ( $10^{5}$ unidades formadoras de colônias por grama (UFC/g); LACT9: Lactobacillus plantarum $\left(10^{9} \mathrm{UFC} / \mathrm{g}\right)$; *Frequência = número de observações de cada fungo dividido pelo número de isolados.**Gênero de fungo mais frequente $(\mathrm{P}<0,01$, teste do qui-quadrado).

Fonte: Autores (2021).

Geralmente a presença dos fungos são resultados de práticas inadequadas no manejo da silagem, já que a maioria das espécies são aeróbicos, portanto, não se desenvolvem em silagem bem preservada. Os fungos comumente detectados nas silagens são Penicillium roqueforti e P. paneum, Monascus ruber, Aspergyllus fumigatus, Byssochlamys nivea, Mucoraceae (em particular Rhizopus nigricans) e Chrysonilia sitophila (Driehuis, 2011).

\section{Conclusão}

A inoculação com as concentrações da cepa de L. plantarum, não alterou o pH de abertura e após 48 horas, as perdas de matéria seca, produção de efluente e estabilidade aeróbica do capim-elefante pré-emurchecido e fermentado.

As contagens de bactérias láticas, fungos micelianos e leveduras também não foram influenciados pela inclusão dessa bactéria. Entretanto, a inoculação da cepa bacteriana reduz a população de Enterobacteriaceae em um log de UFC/g de forragem fermentada e inibe o crescimento bactérias patogênicas não fermentadoras de lactose.

\section{Agradecimentos}

À Coordenação de Aperfeiçoamento de Pessoal de Nível Superior (CAPES, Código Financeiro 0001), Fundação de Amparo à Pesquisa de Minas Gerais (FAPEMIG), Conselho Nacional de Desenvolvimento Científico e Tecnológico (CNPq), PróReitoria de Pesquisa da Universidade Federal de Minas Gerais (PRPq-UFMG) e a Connan - Nutrição Animal. 
Research, Society and Development, v. 10, n. 10, e309101018813, 2021

(CC BY 4.0) | ISSN 2525-3409 | DOI: http://dx.doi.org/10.33448/rsd-v10i10.18813

\section{Referências}

Alvares, C. A., Stape, J. L., Sentelhas, P. C., Gonc, Alves, J. L. M., \& Sparovek, G. (2013). Köppen's climate classification map for Brazil. Meteorol. Z 22, 711 728.

Borreani, G., Tabacco, E., Schmidt, R. J., Holmes, B. J., \& Muck, R. E. (2018). Silage review: Factors affecting dry matter and quality losses in silages. Journal of Dairy Science, 101(5), 3952-3979. https://doi.org/10.3168/jds.2017-13837

Bumbieris, J. V. H., Oliveira, M. R., Barbosa, M. A. A. F., \& Jobim, C.C. (2011). Use of winter cultures for forage conservation. International Syposium on Forage Quality and Conservation. 2, 65-84.

Daniel, J. L. P., Bernardes, T. F., Jobim, C. C, Schmidt, P., \& Nussio, L. G. (2019). Production and utilization of silages in tropical areas with focus on Brazil. Grass and Forage Science, 74(2), 188-200. https://doi.org/10.1111/gfs.12417

Driehuis, F. (2011). Ocorrência de micotoxinas na silagem. In: II Simpósio Internacional of Forage Quality and Conservation, São Pedro, Anais. São Pedro: Simpósio Internacional of Forage Quality and Conservation, 85-104.

Dugan, F. M. (2006). The identification of fungi: an illustrated introduction with keys, glossary, and guide to literature. St. Paul, Minn.: American Phytopathological Society, 176 .

Evangelista, A. R., Siqueira, G. R., Lima, J. Á., Lopes, J., \& Rezende, A. V. (2009). Alterações bromatológicas e fermentativas durante o armazenamento de silagens de cana-de-açúcar com e sem milho desintegrado com palha e sabugo. Revista Brasileira de Zootecnia, 38, 20-26. doi:10.1590/S1516-3598200900010000

Ferreira, D. J., Lana, R. P., Zanine, A. M, Santos, E. M., Veloso, C. M., \& Ribeiro, G. A. (2013). Silage fermentation and chemical composition of elephant grass inoculated with rumen strains of Streptococcus bovis. Animal Feed Science and Technology, 183, 22-28. https://doi.org/10.1016/j.anifeedsci.2013.04.020

Ferreira, D. J., Zanine, A. M., Lana, R. P., Ribeiro, M. D., Alves, G. R., \& Mantovani, H. C. (2014). Chemical composition and nutrient degradability in elephant grass silage inoculated with Streptococcus bovisis olated from the rumen. In: Anais da Academia Brasileira de Ciências, 86, 465-474. https://doi.org/10.1590/000137652014112312

Guimarães, C. G., Bonfá, C. S., Evangelista, A. R., Santos, A. S. D., Pantoja, L. D. A., \& Castro, G. H. D. F. (2018). Fermentation characteristics of elephant grass silages with macaúba cake. Acta Scientiarum. Animal Sciences, on-line, 40. doi:10.4025/actascianimsci.v40i1.42523

Lane D. J. (1991). 16S/23S rRNA sequencing In: E Stackebrandt and M Good fellow, ed Nucleic Acid Techniques in Bacterial Systematics. Chichester: Wiley. $115-175$.

Maijala R., Ranta J., \& Seuna E. (2005)., The efficiency of the Finnish Salmonella Control Programme. Food Control, 16(8), 669-675. Disponível em: https://doi.org/10.1016/j.foodcont.2004.06.003

Mcdonald, P., Henderson, A. R., \& Heron. S. J. E. (1991). The biochemistry of silage. New York: JohnWiley, 226.

Murray, P., Baron, E. J., Jorgensen, J. H., Pfaller, M. A., \& Yolken, R. H. (2007). Manual of Clinical Microbiology. 9th ed. American Society for Microbiology, Washington, DC, 2488.

Nussio, L. G. (2005). Silage production from tropical forages. In R. S. Park, M. D. Stronge (Eds.), Proceedings of the XIV International Silage Conference, Belfast, UK, Anais. Belfast, UK: Proceedings of the XIV International Silage Conference, 97-107.

Renhe, I. R. T., Volp, A., Vidigal, J., \& Stringheta, P. (2006). Monascus na nutrição e saúde. Brazilian Jornal of Food and Nutrition, 17(3), $337-343$.

Ribeiro, L., Pires, A. J. V., Carvalho, G. G. P. De, Pereira, M., Santos, A. B. dos, \& Rocha, L. C. (2014). Características fermentativas, composição química e fracionamento de carboidratos e proteínas de silagem de capim-elefante emurchecido ou com adição de torta de mamona. Semina: Ciências Agrárias, 35, 14471462. doi:10.5433/1679-0359.2014v35n3p1447

Silva, D. J., \& Queiroz, A. C. (2002). Análise de Alimentos: métodos químicos e biológicos. 3.ed. Viçosa: UFV, 235. Revista Ciência Agronômica, 41, 482-489. doi:10.1590/S1806-66902010000300023

Silva, S., \& Xará, S. (2013). Levedura de arroz vermelho no tratamento da hipercolesterolemia. Revista Nutrícias, (19), 24-27.

Tomaz, P. K., Araujo, L. C. De, Sanches, L. A., Araujo, S. N. S. Dos, De Lima, T. O., Lino, A. D. A., \& Ferreira, E. M. (2018). Effect of sward height on the fermentability coefficient and chemical composition of Guinea grass silage. Grass and Forage Science, 73, 588-598. https://doi.org/10.1111/gfs.12349

Veloso, V. A. (2016). Bactérias láticas com potencial probiótico provenientes de bezerros leiteiros desmamados criados no semiárido. Monografia, Instituto de Ciências Agrárias da UFMG.

Zhang, Y. C., LI, D. X., Wang, X. K., Lin, Y. L., Zhang, Q., Chen, X. Y., \& Yang, F. Y. (2019). Fermentation quality and aerobic stability of mulberry silage prepared with lactic acid bacteria and propionic acid. Animal Science Journal. 90(4), 513-522. https://doi.org/10.1111/asj.13181

Yuan, X., Guo, G., Wen, A., Desta, S. T., Wang, J., Wang, Y., \& Shao, T. (2015). The effect of different additives on the fermentation quality, in vitro digestibility and aerobic stability of a total mixed ration silage. Animal Feed Science and Technology, 207, 41-50. https://doi.org/10.1016/j.anifeedsci.2015.06.001 